\title{
The efficacy of the time-scheduled decremental continuous infusion of fentanyl for postoperative patient-controlled analgesia after total intravenous anesthesia
}

\author{
Jong-Yeop Kim, Sung-Yong Park, Hyuk Soo Chang, Si-Kwon Nam, and Sang-Kee Min \\ Department of Anesthesiology and Pain Medicine, Ajou University School of Medicine, Suwon, Korea
}

Background: Intravenous fentanyl has been used for acute postoperative pain management, but has not always provided reliable adequate analgesia, including patient-controlled analgesia (PCA). The purpose of this study was to investigate the efficacy of time-scheduled decremental infusion of fentanyl for postoperative analgesia.

Methods: Ninety-nine patients, aged 20-65 years, undergoing laparoscopic-assisted hysterectomy using total intravenous anesthesia (TIVA) were randomly assigned into one of the three groups. Their background infusions of fentanyl diluent ( $2 \mathrm{ml} / \mathrm{hr}$ of diluent was equivalent with $0.5 \mu \mathrm{g} / \mathrm{kg} / \mathrm{hr}$ of fentanyl) with PCA were maintained at the fixed-rate of $2 \mathrm{ml} / \mathrm{hr}$ until the postoperative $24 \mathrm{hr}$ (FX2-2-2), or at the decremental rates of 6.0, 4.0, $2.0 \mathrm{ml} / \mathrm{hr}$ (D6-4-2) and 8.0, 4.0, $2.0 \mathrm{ml} / \mathrm{hr}$ (D8-4-2). The visual analogue score (VAS), incidence of inadequate analgesia, frequency of PCA intervention, and side effects were evaluated.

Results: VAS was significantly higher in FX2-2-2 than in D6-4-2 and D8-4-2 until postoperative $3 \mathrm{hr}(\mathrm{P}<0.05)$. After postoperative $4 \mathrm{hr}$, VAS was significantly higher in FX2-2-2 than D8-4-2 $(\mathrm{P}<0.05)$. The incidence of inadequate analgesia of FX2-2-2 was significantly greater than D6-4-2 ( $\mathrm{P}=0.038)$ and D8-4-2 $(\mathrm{P}<0.001)$ until postoperative $1 \mathrm{hr}$. None of the patients had ventilatory depression, and postoperative nausea and vomiting were not significant among the groups.

Conclusions: The time-scheduled decremental background infusion regimens of fentanyl, based on the pharmacokinetic model, could provide more effective postoperative pain management after TIVA, and the side effects and the risk for morbidity were not different from the fixed-rate infusion regimen. (Korean J Anesthesiol 2013; 65: 544-551)

Key Words: Fentanyl, Intravenous anesthesia, Patient-controlled analgesia.

Received: May 8, 2013. Revised: 1st, May 24, 2013; 2nd, June 7, 2013; 3rd, June 13, 2013. Accepted: June 14, 2013.

Corresponding author: Sang-Kee Min, M.D., Department of Anesthesiology and Pain Medicine, Ajou University School of Medicine, San 5, Woncheon-dong, Paldal-gu, Suwon 442-721, Korea. Tel: 82-31-219-5572, Fax: 82-31-219-5579, E-mail: anesmin@nate.com

(c) This is an open-access article distributed under the terms of the Creative Commons Attribution Non-Commercial License (http:// creativecommons.org/licenses/by-nc/3.0/), which permits unrestricted non-commercial use, distribution, and reproduction in any medium, provided the original work is properly cited. 


\section{Introduction}

Total intravenous anesthesia (TIVA) has the merit of rapid and predictable emergence from anesthesia. However, the rapid offset of short-acting intravenous agents, while desirable, may incur inadequate postoperative analgesia. Thus, active intervention and careful transition from intraoperative to postoperative analgesia must be established. Fentanyl is a common opiate for postoperative analgesia, and its minimum effective plasma concentration $\left(\mathrm{C}_{\mathrm{p}}\right)$ was reported as $0.63 \mathrm{ng} / \mathrm{ml}$, ranging from 0.23 to $1.18 \mathrm{ng} / \mathrm{ml}$ [1]. The primary hyperalgesia due to skin incision was reported to subside within $1 \mathrm{hr}$, but the secondary hyperalgesia was known to develop maximally within $30 \mathrm{~min}$ and persist for $3 \mathrm{hr}$ [2]. Furthermore, various studies on the postoperative analgesia using intravenous fentanyl show that postoperative pain scores remains high until 4 or $6 \mathrm{hr}$ postoperatively [3-9].

Intravenous postoperative pain management, using shortacting opiates, usually involves a continuous background infusion, and a patient-controlled analgesia (PCA). However, the pharmacokinetic/pharmacodynamic (PK/PD) simulations of fentanyl, using the PK/PD software (STANMUMP ${ }^{\complement}$, SL Shafer, Department of Anesthesia, Columbia University, New York, NY, USA) with the weight-scaled three-compartment PK model [10] and the effect-site compartment [11,12] (Table 1), showed delayed increases to a steady-state of the effect-site concentration $\left(\mathrm{C}_{\text {eff }}\right)$ during various fixed-amount infusions following 1.0 $\mu \mathrm{g} / \mathrm{kg}$ of initial bolus, which were more predominant at lower rate background infusions (Fig. 1). Therefore, the analgesic concentration in the body might be insufficient to the severity of the early postoperative pain during the fixed-rate infusion of the recommended regimens $(<1.1 \mu \mathrm{g} / \mathrm{kg} / \mathrm{hr})[1,5,7,13,14]$. But fixed-set to higher rates $(1.25-2.0 \mu \mathrm{g} / \mathrm{kg} / \mathrm{hr})[6,13] \mathrm{might}$ increase the risk of side effects, such as ventilatory depression, while $50 \%$ depressing the slope of the ventilation- $\mathrm{CO}_{2}$ response curve at the $\mathrm{C}_{\mathrm{p}}$ of fentanyl between $2.0-3.1 \mathrm{ng} / \mathrm{ml}$ [15].

Therefore, we established time-scheduled decremental background infusions of fentanyl, which were programmed to cope with the time course of postoperative analgesia after propofol/

Table 1. The Pharmacokinetic/pharmacodynamic Microconstants of the Weight-scaled Three-compartment Pharmacokinetic Model [10] with Effect-site Compartment $[11,12]$ Used for the Simulations of the Administration of Fentanyl

\begin{tabular}{ll}
\hline $\mathrm{Vc}_{\mathrm{c}}(\mathrm{L} / \mathrm{kg})$ & 0.105 \\
$\mathrm{~K}_{10}(/ \mathrm{min})$ & 0.0798 \\
$\mathrm{~K}_{12}(/ \mathrm{min})$ & 0.4514 \\
$\mathrm{~K}_{13}(/ \mathrm{min})$ & 0.1895 \\
$\mathrm{~K}_{21}(/ \mathrm{min})$ & 0.1063 \\
$\mathrm{~K}_{31}(/ \mathrm{min})$ & 0.0059 \\
$\mathrm{~K}_{\mathrm{e} 0}(/ \mathrm{min})$ & 0.147 \\
\hline
\end{tabular}

remifentanil-based TIVA, and their efficacy and safety were compared with those of the fixed-rate background infusion.

\section{Materials and Methods}

This study was approved by the Institutional Review Board and written informed consent was obtained from all patients. A total of 99 female patients of American Society of Anesthesiologists physical status 1-2 and aged 20-65 years, who wanted postoperative pain management after laparoscopic-assisted hysterectomy, were enrolled in this study. Exclusion criteria included a history of neurologic, psychiatric, endocrinologic, renal or hepatic disorders. Drug or alcoholic abusers and patients taking analgesics or sedatives were also excluded. The instructions of pain control device and the expression method of the pain intensity were explained at the pre-anesthetic visit.

The anesthetic technique of TIVA was standardized. As a premedication, glycopyrrolate $0.2 \mathrm{mg}$ was administered intravenously, but no sedatives and opiates were given. Routine monitoring consisted of electrocardiograph, pulse oximetry, non-invasive arterial pressure, end-tidal carbon dioxide partial pressure, and bispectral index (BIS). TIVA was induced using propofol (Fresofol ${ }^{\circledR}$, Fresenius Kabi, Homburg, Germany) and remifentanil (Ultiva ${ }^{\mathrm{TM}}$, GlaxoSmithKline, Rixensart, Belgium) target-controlled infusions (TCI), which were administered using two-channel infusion pump (Orchestra ${ }^{\circledR}$, Fresenius Vial, Brezins, France) with corresponding PK/PD models [16,17]. For neuromuscular blockade, $0.6 \mathrm{mg} / \mathrm{kg}$ of rocuronium was given

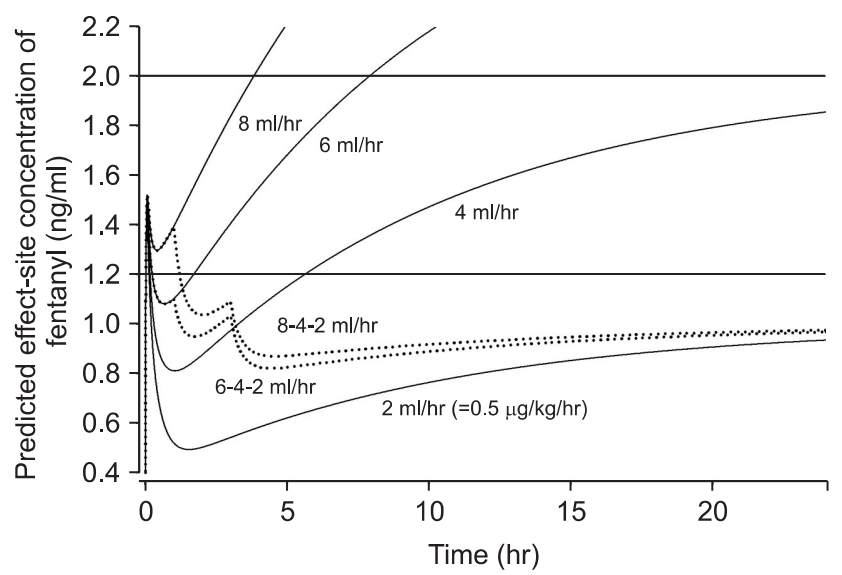

Fig. 1. Time-courses of the simulated effect-site concentrations $\left(\mathrm{C}_{\text {eff }}\right)$ of fentanyl during the continuous infusion of 2, 4, 6 and $8 \mathrm{ml} / \mathrm{hr}$ of diluent (solid curves) after $1.0 \mu \mathrm{g} / \mathrm{kg}$ of bolus injection. The infusion rate of 2 $\mathrm{ml} / \mathrm{hr}$ of diluent was equivalent with $0.5 \mu \mathrm{g} / \mathrm{kg} / \mathrm{hr}$ of fentanyl. The dotted curves indicate the decremental infusions; $8 \mathrm{ml} / \mathrm{hr}(8-4-2 \mathrm{ml} / \mathrm{hr})$ and 6 $\mathrm{ml} / \mathrm{hr}$ (6-4-2 $\mathrm{ml} / \mathrm{hr}$ ) during $0-1 \mathrm{hr}$ postoperatively, $4 \mathrm{ml} / \mathrm{hr}$ during 1-3 $\mathrm{hr}$, and thereafter $2 \mathrm{ml} / \mathrm{hr}$. The horizontal lines indicates the reference levels of fentanyl for the risk of respiratory depression $\left(C_{\text {eff }}=2.0 \mathrm{ng} / \mathrm{ml}\right)$, and for the effective analgesic concentration $\left(\mathrm{C}_{\mathrm{eff}}=1.2 \mathrm{ng} / \mathrm{ml}\right)$. 
by IV. After tracheal intubation, propofol and remifentanil TCIs were titrated to maintain BIS of between 40-60, and systolic blood pressure and heart rate as $\pm 20 \%$ of baseline values. Any patient who needed to receive opiates and analgesics other than remifentanil was designed to be excluded from this study. Single intravenous palonosetron $0.075 \mathrm{mg}$ was administered after the induction of anesthesia to prevent the postoperative nausea and vomiting (PONV) [18]. Postoperative pain management was prepared during surgery and performed at the end of TIVA, as follows.

A balloon-type, disposable infuser (Auto-Fusor ${ }^{\circledR}$, AceMedical Corp., Ltd, Seoul, Korea), which had a module for PCA and a basal infusion rate controller (AutoSelector ${ }^{\circledR}$, AceMedical Corp., Ltd, Seoul, Korea), was filled with $100 \mathrm{ml}$ of fentanyl diluent (Fentanyl citrate ${ }^{\circledR}$, Hana Pharm. Co., Seoul, Korea), which was prepared by an anesthesiologist who was otherwise not involved in the postoperative pain assessment. According to body weight, individual fentanyl diluent was made to be equivalent to $0.25 \mu \mathrm{g} / \mathrm{kg}$ of fentanyl per $1.0 \mathrm{ml}$ of diluent, using normal saline. During the surgery, the infuser and its extension lines were primed while diluent was evacuated to atmosphere. When the skin closure started, propofol/remifentanil TCI stopped. Thereafter, fentanyl diluent $4 \mathrm{ml}(=1.0 \mu \mathrm{g} / \mathrm{kg})$ was injected during 30 $\mathrm{s}$ [19], when the $\mathrm{C}_{\text {eff }}$ of remifentanil TCI decreased to $2.0 \mathrm{ng} / \mathrm{ml}$ [20]. The infuser was connected at the proximal portion of the indwelling cannula of the patient using three-way stopcock, and an anti-reflux one-way valve was inserted to prevent the backflow to the gravity infusion line for anticipating an occlusion.

Patients were randomized to one of the three groups (FX2-22, D6-4-2 and D8-4-2) consisting of 33 patients in each group, using Excel ${ }^{\complement}$ 'Random' function (Microsoft Office ${ }^{\circledR}$ Excel 2007). In FX2-2-2, the background infusion rate was maintained at a fixed-rate of $2.0 \mathrm{ml} / \mathrm{hr}$ until postoperative $24 \mathrm{hr}$, without changing the infusion rate [5,7]. In decremental infusion groups, the infusion rates were maintained at $6.0 \mathrm{ml} / \mathrm{hr}$ (D6-4-2) and 8.0 $\mathrm{ml} / \mathrm{hr}$ (D8-4-2) until postoperative $1 \mathrm{hr}$, respectively, and decreased to maintain at $4.0 \mathrm{ml} / \mathrm{hr}$ during postoperative $1-3 \mathrm{hr}$. Thereafter, they were decreased to $2.0 \mathrm{ml} / \mathrm{hr}$ during postoperative 3-24 hr (Fig. 1). PCA bolus amount was $1.0 \mathrm{ml}(=0.25 \mu \mathrm{g} /$ $\mathrm{kg}$ ) with $15 \mathrm{~min}$ of filling time. When the patients opened their

Table 2. Observer's Objective Assessment of Pain Scores (OOAPS)

\begin{tabular}{|c|c|c|c|}
\hline & 0 & 1 & 2 \\
\hline General appearance & Calm & Restless & Agitated \\
\hline Grimace & No & Only forehead & Whole face \\
\hline Moaning sound & No & Quiet & Loud \\
\hline Posture & Relaxed & Extremity flexion & $\begin{array}{l}\text { Truncal flexion, } \\
\text { or roll-over }\end{array}$ \\
\hline Demand for analgesics & No & Passively & Actively \\
\hline
\end{tabular}

eyes, deep breathing was encouraged, and extubation was done, after the reversal of residual neuromuscular blockage using glycopyrrolate $0.4 \mu \mathrm{g} / \mathrm{kg}$ and pyridostigmine $0.2 \mathrm{mg} / \mathrm{kg}$. The patient was then transported to the postanesthesia care unit (PACU).

Routine monitoring was implemented at PACU, and the Aldrete three-point postanesthesia recovery score that assessed five areas (activity, respiration, blood pressure, color, and level of consciousness) was measured at 5-min intervals [21]. The efficacy of analgesia was assessed both subjectively and objectively, at 15 min interval: (i) Patient was asked to state a graded visual analogue scale (VAS, at rest, no pain $=0$, the worst possible pain =10), subjectively. (ii) An investigator, blinded to the group allocation, evaluated the analgesia using 'Observer's Objective assessment of pain scores' (OOAPS) (Table 2). The total up of the five areas' scores was defined as OOAPS. The primary efficacy measures of this study included 'inadequate analgesia' in the PACU, which was defined to be at least one more episode of 'VAS $>3$ or OOAPS $>0$ ' at every 15 min-interval assessments of pain. When a patient showed inadequate analgesia, fentanyl diluent 1 $\mathrm{ml}(=0.25 \mu \mathrm{g} / \mathrm{kg})$ was administered using PCA module, and in case of inadequate analgesia at the final assessment of pain in the $\mathrm{PACU}$, ketorolac $30 \mathrm{mg}$ IV was given as a rescue analgesic. After one hour of PACU care, the patient who had obtained higher than 8 points of the recovery score was transported to the general ward. The patient was instructed to use PCA voluntarily in the ward and to record the time of PCA episode using lap-time memory of stopwatch. Ketorolac $30 \mathrm{mg}$ iv was also administered as a rescue analgesic in the ward. The assessments of analgesia and patient condition were performed at the time points of postoperative 2, 3, 4, 6, 12 and $24 \mathrm{hr}$.

The following end points in the PACU and ward were examined: VAS change, PCA episode, rescue analgesics, alertness, ventilatory depression (respiration rate $<6 / \mathrm{min}$ ), bradycardia (heart rate $<20 \%$ of baseline), PONV, headache, and dizziness. The intensities of PONV were measured using a four-point categorical scale of 'none' to 'severe', and palonosetron $0.025 \mathrm{mg}$

Table 3. Patient Characteristics

\begin{tabular}{lrrr}
\hline & $\begin{array}{r}\text { FX2-2-2 } \\
(\mathrm{n}=33)\end{array}$ & $\begin{array}{r}\mathrm{D} 6-4-2 \\
(\mathrm{n}=33)\end{array}$ & $\begin{array}{c}\text { D8-4-2 } \\
(\mathrm{n}=33)\end{array}$ \\
\hline Age $(\mathrm{yr})$ & $44.8 \pm 6.9$ & $41.4 \pm 8.9$ & $43.1 \pm 9.5$ \\
Weight $(\mathrm{kg})$ & $59.5 \pm 8.7$ & $59.5 \pm 8.8$ & $60.1 \pm 7.1$ \\
Height $(\mathrm{cm})$ & $159.0 \pm 5.3$ & $160.6 \pm 3.5$ & $158.7 \pm 4.9$ \\
Duration of surgery (min) & $95 \pm 27$ & $93 \pm 31$ & $90 \pm 27$ \\
Duration of anesthesia (min) & $117 \pm 28$ & $113 \pm 33$ & $114 \pm 27$ \\
\hline
\end{tabular}

Values represent mean \pm SD. Their background infusions of fentanyl diluent were maintained at the fixed-rate of $2 \mathrm{ml} / \mathrm{hr}$ (FX2-2-2), or at the decremental rates of 6.0, 4.0, $2.0 \mathrm{ml} / \mathrm{hr}(\mathrm{D} 6-4-2)$ and 8.0, 4.0, $2.0 \mathrm{ml} / \mathrm{hr}$ (D8-4-2) until the postoperative $24 \mathrm{hr}$. 
was administered as a rescue therapy according to the patient's request. When assuming the severe side effects of fentanyl, background infusions were reduced to $1.0 \mathrm{ml} / \mathrm{hr}$. At the last visit of postoperative $24 \mathrm{hr}$, or at the time of withdrawal from the study, the satisfaction score on the overall postoperative pain management (based on an eleven-point categorical scale of ' 0 = worst' to ' $10=$ best') was asked to the patient, and in case of dissatisfaction, the major reason for that was questioned. Posthoc individual simulation of the time-course of $\mathrm{C}_{\text {eff }}$ of fentanyl was performed based on each background infusion rate and the recorded lap time of PCA demand, using the same PK/PD software described above.

For the calculation of the sample size, a pilot study was conducted for 30 patients given the bolus and background infusion same as this study, which showed $80.0 \%$ of 'inadequate analgesia' during $0.5 \mu \mathrm{g} / \mathrm{kg} / \mathrm{hr}$ and $46.7 \%$ at $1.5 \mu \mathrm{g} / \mathrm{kg} / \mathrm{hr}$ of background infusions in the PACU. To obtain a two-sided test of difference using $\alpha=0.05$ and $\beta=0.2$, the sample size was estimated at 33 evaluation subjects per group.

Statistical analyses were executed using SPSS 10.0 for windows (SPSS Inc, Chicago, IL, USA). Data are expressed as mean

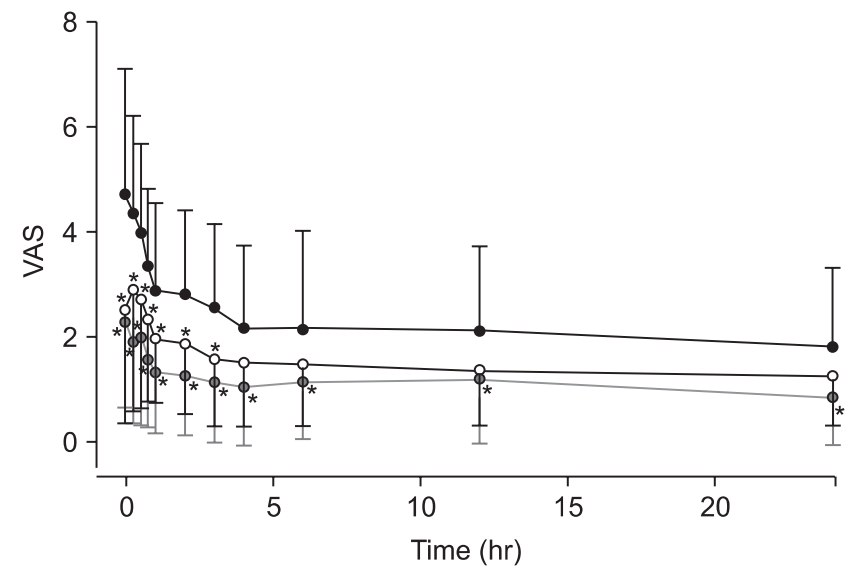

Fig. 2. Time-courses of the visual analogue scale (VAS) during the postoperative analgesia. The background infusions were maintained at the fixed-rate of $2 \mathrm{ml} / \mathrm{hr}$ until the postoperative $24 \mathrm{hr}$ (black circle), and at the decremental rates of $6 \mathrm{ml} / \mathrm{hr}$ (white circle) and $8 \mathrm{ml} / \mathrm{hr}$ (gray circle) during the postoperative $1 \mathrm{hr}, 4 \mathrm{ml} / \mathrm{hr}$ during $1-3 \mathrm{hr}$ and $2 \mathrm{ml} / \mathrm{hr}$ during 3-24 hr, postoperatively. The infusion rate of $2 \mathrm{ml} / \mathrm{hr}$ of diluent was equivalent with $0.5 \mu \mathrm{g} / \mathrm{kg} / \mathrm{hr}$ of fentanyl. $* \mathrm{P}<0.05$ compared with the fixed-rate infusion group.

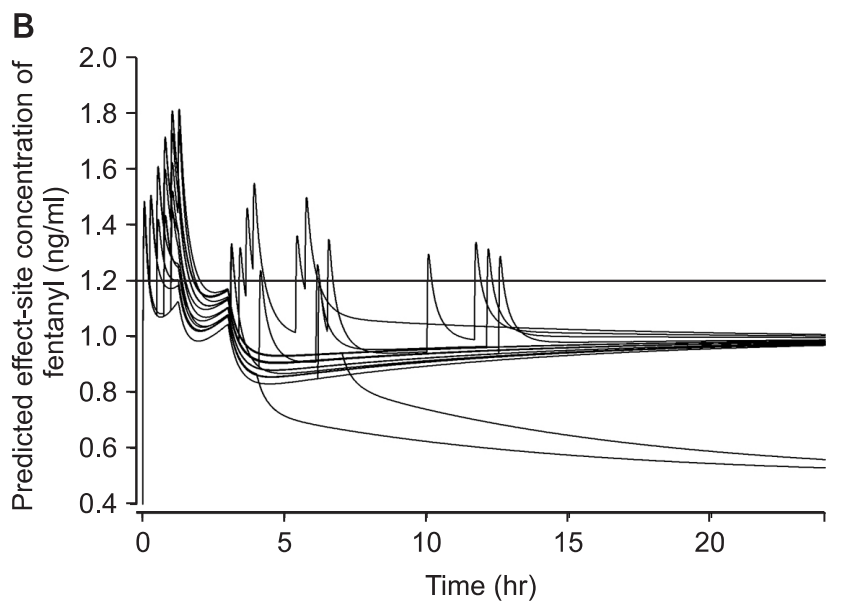

Fig. 3. Individual time-courses of predicted effect-site concentration of fentanyl administered for a postoperative analgesia using the patientcontrolled analgesia with the concurrent background infusions. The background infusions were maintained at the fixed-rate of $2 \mathrm{ml} / \mathrm{hr}$ until the postoperative $24 \mathrm{hr}(\mathrm{A})$, and at the decremental rates of $6 \mathrm{ml} / \mathrm{hr}$ (B) and $8 \mathrm{ml} / \mathrm{hr}$ (C) during the postoperative $1 \mathrm{hr}, 4 \mathrm{ml} / \mathrm{hr}$ during $1-3 \mathrm{hr}$ and $2 \mathrm{ml} / \mathrm{hr}$ during 3-24 hr, postoperatively. The infusion rate of $2 \mathrm{ml} /$ $\mathrm{hr}$ of diluent was equivalent with $0.5 \mu \mathrm{g} / \mathrm{kg} / \mathrm{hr}$ of fentanyl. 
Table 4. Analgesic Profiles during the Postoperative Analgesia using Fentanyl Diluent

\begin{tabular}{|c|c|c|c|}
\hline & $\begin{array}{l}\text { FX2-2-2 } \\
(\mathrm{n}=33)\end{array}$ & $\begin{array}{l}\text { D6-4-2 } \\
(\mathrm{n}=33)\end{array}$ & $\begin{array}{l}\text { D8-4-2 } \\
(\mathrm{n}=33)\end{array}$ \\
\hline \multicolumn{4}{|l|}{ At PACU, } \\
\hline Inadequate analgesia (\%) & $78.8(26 / 33)$ & $48.5(17 / 33)^{*}$ & $21.2(7 / 33)^{*,+}$ \\
\hline Maximal VAS & $4.9 \pm 2.0$ & $3.4 \pm 2.3^{*}$ & $2.7 \pm 1.7^{*}$ \\
\hline Maximal OOAPS & $2.4 \pm 2.6$ & $1.0 \pm 1.5^{*}$ & $0.3 \pm 0.7^{*}$ \\
\hline PCA episodes & $2.9 \pm 1.9$ & $1.3 \pm 1.5^{*}$ & $0.5 \pm 0.9^{*}$ \\
\hline Rescue analgesics (\%) & $27.3(9 / 33)$ & $6.1(2 / 33)^{*}$ & $0(0 / 33)^{*}$ \\
\hline Minimal respiration rate $(/ \mathrm{min})$ & $12.7 \pm 3.2$ & $13.6 \pm 2.7$ & $13.4 \pm 2.8$ \\
\hline \multicolumn{4}{|l|}{ At ward, } \\
\hline Inadequate analgesia (\%) & $30.3(10 / 33)$ & $9.1(3 / 33)$ & $0(0 / 33) *$ \\
\hline Maximal VAS & $3.2 \pm 1.9$ & $1.9 \pm 1.3^{*}$ & $1.5 \pm 1.3^{*}$ \\
\hline PCA episodes & $2.6 \pm 4.5$ & $0.5 \pm 1.2^{*}$ & $0.3 \pm 0.9^{*}$ \\
\hline Rescue analgesics (\%) & $18.2(6 / 33)$ & $6.1(2 / 33)$ & $3.0(1 / 33)$ \\
\hline
\end{tabular}

Values represent mean \pm SD or percentage (numbers of patients). The background infusions of fentanyl diluent were maintained at the fixed-rate of $2 \mathrm{ml} / \mathrm{hr}$ (FX2-2-2), or at the decremental rates of 6.0, 4.0, $2.0 \mathrm{ml} / \mathrm{hr}$ (D6-4-2) and 8.0, 4.0, $2.0 \mathrm{ml} / \mathrm{hr}$ (D8-4-2) until the postoperative $24 \mathrm{hr}$. PACU: postanesthesia care unit, VAS: visual analogue scale, OOAPS: observer's objective assessment of pain score, PCA: patient-controlled analgesia. ${ }^{*} \mathrm{P}<0.05$ compared with FX2-2-2 group, ${ }^{\dagger} \mathrm{P}<0.05$ compared with D6-4-2 group.

$\pm \mathrm{SD}$ or number of patients (\%). Categorical variables were compared using chi-square, or Fisher's exact test, where appropriate. Repeated-measures ANOVA were used to compare VAS changes over time among the groups, followed by Duncan's post-hoc testing. Continuous variables between the groups were compared by using one-way ANOVA with Bonferroni post-hoc testing. Null hypotheses of no difference were rejected if $P$ values were less than 0.05 .

\section{Results}

Patient characteristics including age, body weight, height, and the duration of surgery and anesthesia, had no statistically significant differences for patients among groups (Table 3). All ninety-nine patients completed the study with no withdrawal; however, the background infusions of 5 patients had to be decreased to $1 \mathrm{ml} / \mathrm{hr}$ at ward because of severe PONV. There were statistically significant within-group effects of time on the postoperative VAS change $(\mathrm{P}<0.001)$. The difference in VAS over time was statistically significant between groups $(\mathrm{P}<0.001)$ (Fig. 2). VAS was significantly higher in the FX2-2-2 group than in the D6-4-2 and D8-4-2 groups from immediate postoperative period to postoperative $3 \mathrm{hr}(\mathrm{P}<0.05)$. After postoperative $4 \mathrm{hr}$, VAS was significantly higher in the FX2-2-2 group than in the D8-4-2 group $(\mathrm{P}<0.05)$ (Fig. 2). Individual time courses of predicted $\mathrm{C}_{\text {eff }}$ are illustrated at Fig. 3. However each graph has not demonstrated 33 individual curves, because the subjects who had not used the PCA module were simulated to have the same time courses of $\mathrm{C}_{\text {eff. }}$.

\section{Analgesic efficacy}

At PACU, the proportion of patients with inadequate anal-
Table 5. Side Effects and Patient's Satisfaction during the Postoperative Analgesia using Fentanyl Diluent

\begin{tabular}{lccc}
\hline & $\begin{array}{c}\text { FX2-2-2 } \\
(\mathrm{n}=33)\end{array}$ & $\begin{array}{c}\text { D6-4-2 } \\
(\mathrm{n}=33)\end{array}$ & $\begin{array}{c}\mathrm{D} 8-4-2 \\
(\mathrm{n}=33)\end{array}$ \\
\hline PONV & & & \\
$\quad$ Incidence (\%) & $30.3(10 / 33)$ & $39.4(13 / 33)$ & $45.5(15 / 33)$ \\
$\quad$ Severity & & & \\
$\quad$ Mild & 7 & 8 & 9 \\
$\quad$ Moderate & 1 & 3 & 5 \\
$\quad$ Severe & 2 & 2 & 1 \\
Onset time (hr) & $6.0 \pm 2.8$ & $9.5 \pm 6.5$ & $5.4 \pm 2.9$ \\
Headache (\%) & $3.0(1 / 33)$ & $6.1(2 / 33)$ & $6.1(2 / 33)$ \\
Dizziness (\%) & $18.2(6 / 33)$ & $45.5(15 / 33) *$ & $51.5(17 / 33) *$ \\
Patient's satisfaction & & & \\
Score & $8.0 \pm 2.2$ & $7.8 \pm 1.7$ & $7.5 \pm 1.7$ \\
Reason for dissatisfaction & & & \\
$\quad$ Pain & $4 / 33$ & - & - \\
$\quad$ PONV & $7 / 33$ & $9 / 33$ & $14 / 33$ \\
Headache & - & $1 / 33$ & $1 / 33$ \\
$\quad$ Dizziness & - & $5 / 33$ & $1 / 33$ \\
$\quad$ Others & $2 / 33$ & - & - \\
\hline
\end{tabular}

Values represent mean \pm SD or number of patients. The background infusions of fentanyl diluent were maintained at the fixed-rate of $2 \mathrm{ml} /$ $\mathrm{hr}$ (FX2-2-2), or at the decremental rates of 6.0, 4.0, $2.0 \mathrm{ml} / \mathrm{hr}$ (D6-42) and 8.0, 4.0, $2.0 \mathrm{ml} / \mathrm{hr}(\mathrm{D} 8-4-2)$ until the postoperative $24 \mathrm{hr}$. PONV: postoperative nausea and vomiting. $* \mathrm{P}<0.05$ compared with FX2-2-2 group.

gesia of FX2-2-2 was significantly greater than the decremental infusion group of D6-4-2 (P = 0.038) and D8-4-2 $(\mathrm{P}<0.001)$ (Table 4$)$. The mean maximal VAS and the mean maximal OOAPS of FX2-2-2 were significantly higher than those of D64-2 and D8-4-2, and the mean episodes of additional fentanyl diluent using PCA bolus in FX2-2-2 was also greater than those of D6-4-2 and D8-4-2. The proportion of patients who required rescue analgesics in FX2-2-2 was greater than in D6-4-2 and D8-4-2. The highest VAS was 9, 7, 7 and the highest OOAPS was 


\section{9, 5, 3 in FX2-2-2, D6-4-2 and D8-4-2, respectively.}

In the ward, compared with the fixed-rate infusion group of FX2-2-2, the proportion of patients with inadequate analgesia was greater than D6-4-2, but statistically not significant ( $\mathrm{P}=$ $0.06)$. However, the proportion of inadequate analgesia of $D 8$ 4-2 was smaller than that of FX2-2-2 ( $\mathrm{P}=0.001)$ (Table 4). The maximal VAS and PCA episodes of FX2-2-2 were significantly greater than those of D6-4-2 and D8-4-2, but the proportion of patients who were administered rescue analgesics were not different among groups. The highest VAS in the ward was 7 in FX2-2-2, and 4 in both D6-4-2 and D8-4-2.

\section{Safety and side effects}

The minimal respiration rates in the PACU were not significantly different among groups, and no patient showed ventilatory depression in the PACU and ward (Table 4). The occurrence and the onset time of PONV were not different among groups (Table 5). No patient showed PONV at PACU, but 5 patients developed severe PONV, and their background infusion rate had to be decreased to $1 \mathrm{ml} / \mathrm{hr}$ at ward. The incidence of headache also did not differ significantly among groups, but the incidence of dizziness in FX2-2-2 was lower than in the decremental groups.

\section{Patient satisfaction}

The levels of patient satisfaction were not different among groups. The reasons for dissatisfaction were in most cases complaint of incomplete postoperative analgesia, PONV and on economic grounds (e.g. high cost) in FX2-2-2. On the contrary, in the decremental infusion groups, most of the dissatisfaction was from PONV.

\section{Discussion}

The regimen of the time-scheduled decremental background infusions of fentanyl for the postoperative analgesia after propofol/remifentanil-based TIVA has been demonstrated to provide less inadequate analgesia and less PCA intervention than the fixed-rate background infusion, especially in the early postoperative period. In addition, no regimens resulted in ventilatory depression, and were not significantly different in terms of PONV.

Some studies have found that concurrent background infusion of morphine was not superior to the sole PCA module for the postoperative analgesia $[22,23]$. On the contrary, with PCA, using short-acting fentanyl alone to maintain adequate analgesia, over $70 \%$ of patients required several re-adjustments to the PCA settings or supplemental boluses, compared to only $20 \%$ of patients during morphine PCA [3]. The background infusion with fentanyl PCA was considered to be necessary for effective analgesia. However, recent studies evaluating the effectiveness of postoperative analgesia using the concomitant background infusion of fentanyl, still had not provided reliable adequate analgesia including PCA bolus and a background infusion [3-9]. Accordingly, we tried to establish the infusion method while varying the infusion rates of the diluents. Along with the result of the preliminary study, to decrease the incidence of the inadequate analgesia over $20 \%$ at the immediate postoperative period, the initial infusion rates had to be maintained three times higher (> $1.5 \mu \mathrm{g} / \mathrm{kg} / \mathrm{hr}$ ) than the previously reported infusion rate $(0.5$ $\mu \mathrm{g} / \mathrm{kg} / \mathrm{hr})$. Hence, the initial infusion rates were chosen as 1.5 and $2.0 \mu \mathrm{g} / \mathrm{kg} / \mathrm{hr}$. However, the rationale for these faster infusion rates might be inferred by the pharmacokinetics of fentanyl, as well as the nature of postoperative pain. The PK simulation of intravenous fentanyl showed that $\mathrm{C}_{\mathrm{p}}$ and $\mathrm{C}_{\text {eff }}$ rapidly increased following a bolus injection, then decreased, however increased slowly during the constant zero-order infusions following a bolus injection (Fig. 1), and in order to rapidly increase the $\mathrm{C}_{\mathrm{p}}$ and $\mathrm{C}_{\text {eff }}$, a much faster infusion rate was needed. However, those faster infusions might increase the possibility of the occurrence of side effects, such as ventilatory depression. Thus, it was decided to decrease the infusion rates to $4 \mathrm{ml} / \mathrm{hr}$ and $2 \mathrm{ml} /$ $\mathrm{hr}$ at the postoperative $1 \mathrm{hr}$ and $3 \mathrm{hr}$ as the simulated concentrations began to increase. The reason for this late increase of $\mathrm{C}_{\mathrm{p}}$ of fentanyl might be considered the slow equilibrium of the peripheral compartments. During the TCI of fentanyl when the $\mathrm{C}_{\mathrm{p}}$ at the central compartment is maintained at a constant level, the concentrations (C2 and C3) at the peripheral compartments become equal to $\mathrm{C}_{\mathrm{p}}$ around at $40 \mathrm{~min}$ for $\mathrm{C} 2$, and $15.7 \mathrm{hr}$ for $\mathrm{C} 3$.

VAS is a practical and familiar assessment of pain intensity during the management of postoperative pain. All patients were educated how to express the pain on the pre-anesthetic visit. In some cases, patients' exact self-reporting of the degree of the pain using VAS seemed to be questionable, even though they had fully awaken. Therefore, an additional scoring system of pain was introduced in this study for an objective assessment of pain intensity. The OOAPS used five-item scales, which were scored from 0 to 2 . Each item was selected from the various pediatric postoperative behavioral pain rating scales [24-26], but the combination of the items of the OOAPS system in our study might reasonably be tested in further investigation as a potential scoring system during the immediate postoperative period.

The most dangerous side effect of opioids during the postoperative analgesia might be the respiratory depression. The background infusion amount of D8-4-2 was 4 times greater than the fixed-infusion group, but the gross inspection of the simulation graphs of the $\mathrm{C}_{\text {eff }}$ of fentanyl (Fig. 3) showed that $\mathrm{C}_{\text {eff }}$ hardly exceeded the $2.0 \mathrm{ng} / \mathrm{ml}$ of $\mathrm{C}_{\text {eff }}$ that had been reported to increase the incidence of ventilatory depression [15], and in D8-4-2 (Fig. 
$3 \mathrm{C}$ ), the $\mathrm{C}_{\text {eff }}$ of fentanyl of two subjects after PCA boluses, approached to $2.0 \mathrm{ng} / \mathrm{ml}$, but no case of respiration rate less than $6 / \mathrm{min}$ was recorded during the period of PACU or ward. At $\mathrm{PACU}$, the routine monitoring equipment might be sufficient to promptly detect and manage ventilatory adverse events, but vigilance is needed to prevent respiratory morbidity in the ward. In case of the accidental occlusion of intravenous infusion route during the long-term infusion at ward, the infusate would flow backward to the gravity line, and the accumulated large amount of fentanyl could be injected rapidly after occlusion release. There is no guarantee that this fatal incident would not take place, and various safety devices, such anti-reflux valve or alarm system, should to be considered.

The overall satisfaction scores on the management of analgesia did not differ significantly among groups. Four patients of FX2-2-2 had complained about the insufficiency of the pain management, while none of the decremental infusion groups had expressed their dissatisfaction on the analgesia. However, the major reason for dissatisfaction was PONV. The incidence of PONV was similar with the previously reported studies using the same prophylactic dose of palonosetron after inhalation anesthesia [18], and also have been reported as $45 \%$ using dexamethasone and ondansetron prophylaxis during intravenous fentanyl PCA [27], where the background infusion rate was 0.4 $\mu \mathrm{g} / \mathrm{kg} / \mathrm{hr}$. The characteristics of the occurrence of PONV in our study as follows; First, it did not happen in the PACU, and this could have been due to the residual propofol which maintained subhypnotic low $\mathrm{C}_{\mathrm{p}}$ during the stay in the PACU [28]. Second, the mean onset time of PONV were about the postoperative 5.4-9 hr. As such, we might anticipate that another downward regulation of background infusion would be helpful for the decrease of the incidence of PONV during fentanyl PCA. However, further research on the regulation time and infusion amount of the background infusion might be required.

There are some caveats to be discussed here. First, the most useful technique for intravenous infusion of opioids may be the TCI for the background infusion and PCA. But the commercially available opioid TCI, such as Remifusor ${ }^{\circledR}$ (Graseby $3500^{\circledR}$ with prototype Remifentanil TCI system, Smiths Medical International, Watford, UK), and various TCI pumps have limitations on use at ward and portability during ambulation. Further development and implementation of a small portable TCI-PCA device would be helpful to regulate the infusion rate automatically. Second, the decremental infusion regimens of this study could be also applied from the start of anesthesia using concurrent infusion of remifentanil or not, and beneficially need less intervention of medical personnel at the postoperative period. However, in case of the hemorrhage or hemodilution during surgery, the PK of fentanyl and the resulting prediction of analgesia might be altered [29]. Third, as previously reported [1], the infusion rate of fentanyl for analgesia showed wide range, inter-individual difference. About twenty percent of patients in FX2-2-2 had adequate analgesia, with predicted $C_{p}$ of fentanyl maintained around $0.5 \mathrm{ng} / \mathrm{ml}$ during PACU, while about twenty patients in D8-4-2 needed supplemental PCA, with $\mathrm{C}_{\mathrm{p}}$ was predicted to maintain above $1.3 \mathrm{ng} / \mathrm{ml}$. Therefore, some challenge tests estimating the postoperative analgesic requirement will be helpful to select an appropriate background infusion rate at the initiation of the infusion diluents [30].

In conclusion, the time-scheduled decremental background infusions of fentanyl for postoperative analgesic management after TIVA could achieve more satisfactory analgesia and needed less PCA intervention of the patient and the medical personnel than the conventional fixed rate background infusion, without any increase of risk and side-effects.

\section{Acknowledgments}

This research was financially supported from the Small and Medium Business Administration of Korea (MD320859), and AceMedical Corp., Ltd, Seoul, Korea.

\section{References}

1. Gourlay GK, Kowalski SR, Plummer JL, Cousins MJ, Armstrong PJ. Fentanyl blood concentration-analgesic response relationship in the treatment of postoperative pain. Anesth Analg 1988; 67: 329-37.

2. Kawamata M, Watanabe H, Nishikawa K, Takahashi T, Kozuka Y, Kawamata T, et al. Different mechanisms of development and maintenance of experimental incision-induced hyperalgesia in human skin. Anesthesiology 2002; 97: 550-9.

3. Howell PR, Gambling DR, Pavy T, McMorland G, Douglas MJ. Patient-controlled analgesia following caesarean section under general anaesthesia: a comparison of fentanyl with morphine. Can J Anaesth 1995; 42: 41-5.

4. Kim HS, Czuczman GJ, Nicholson WK, Pham LD, Richman JM. Pain levels within 24 hours after UFE: a comparison of morphine and fentanyl patient-controlled analgesia. Cardiovasc Intervent Radiol 2008; 31: 1100-7.

5. Kim JJ, Ha MH, Jung SH, Song NW. The efficiency of IV PCA with remifentanil and ketorolac after laparoscopic-assisted vaginal hysterectomy. Korean J Anesthesiol 2011; 61: 42-9. 
6. Bernard JM, Lagarde D, Souron R. Balanced postoperative analgesia: effect of intravenous clonidine on blood gases and pharmacokinetics of intravenous fentanyl. Anesth Analg 1994; 79: 1126-32.

7. Choi SH, Koo BN, Nam SH, Lee SJ, Kim KJ, Kil HK, et al. Comparison of remifentanil and fentanyl for postoperative pain control after abdominal hysterectomy. Yonsei Med J 2008; 49: 204-10.

8. Roussier M, Mahul P, Pascal J, Baylot D, Prades JM, Auboyer C, et al. Patient-controlled cervical epidural fentanyl compared with patientcontrolled i.v. fentanyl for pain after pharyngolaryngeal surgery. Br J Anaesth 2006; 96: 492-6.

9. Butkovic D, Kralik S, Matolic M, Kralik M, Toljan S, Radesic L. Postoperative analgesia with intravenous fentanyl PCA vs epidural block after thoracoscopic pectus excavatum repair in children. Br J Anaesth 2007; 98: 677-81.

10. Shafer SL, Varvel JR, Aziz N, Scott JC. Pharmacokinetics of fentanyl administered by computer-controlled infusion pump. Anesthesiology 1990; 73: 1091-102.

11. Scott JC, Stanski DR. Decreased fentanyl and alfentanil dose requirements with age. A simultaneous pharmacokinetic and pharmacodynamic evaluation. J Pharmacol Exp Ther 1987; 240: 159-66.

12. Shafer SL, Varvel JR. Pharmacokinetics, pharmacodynamics, and rational opioid selection. Anesthesiology 1991; 74: 53-63.

13. Shibutani K, Inchiosa MA Jr, Sawada K, Bairamian M. Pharmacokinetic mass of fentanyl for postoperative analgesia in lean and obese patients. Br J Anaesth 2005; 95: 377-83.

14. Gurbet A, Goren S, Sahin S, Uckunkaya N, Korfali G. Comparison of analgesic effects of morphine, fentanyl, and remifentanil with intravenous patient-controlled analgesia after cardiac surgery. J Cardiothorac Vasc Anesth 2004; 18: 755-8.

15. Cartwright P, Prys-Roberts C, Gill K, Dye A, Stafford M, Gray A. Ventilatory depression related to plasma fentanyl concentrations during and after anesthesia in humans. Anesth Analg 1983; 62: 966-74.

16. Gepts E, Camu F, Cockshott ID, Douglas EJ. Disposition of propofol administered as constant rate intravenous infusions in humans. Anesth Analg 1987; 66: 1256-63.

17. Minto CF, Schnider TW, Egan TD, Youngs E, Lemmens HJ, Gambus PL, et al. Influence of age and gender on the pharmacokinetics and pharmacodynamics of remifentanil. I. Model development. Anesthesiology 1997; 86: 10-23.

18. Kovac AL, Eberhart L, Kotarski J, Clerici G, Apfel C. A randomized, double-blind study to evaluate the efficacy and safety of three different doses of palonosetron versus placebo in preventing postoperative nausea and vomiting over a 72-hour period. Anesth Analg 2008; 107: 43944.

19. Camu F, Van Aken H, Bovill JG. Postoperative analgesic effects of three demand-dose sizes of fentanyl administered by patient-controlled analgesia. Anesth Analg 1998; 87: 890-5.

20. Schraag S, Kenny GN, Mohl U, Georgieff M. Patient-maintained remifentanil target-controlled infusion for the transition to early postoperative analgesia. Br J Anaesth 1998; 81: 365-8.

21. Aldrete JA, Kroulik D. A postanesthetic recovery score. Anesth Analg 1970; 49: 924-34.

22. Parker RK, Holtmann B, White PF. Effects of a nighttime opioid infusion with PCA therapy on patient comfort and analgesic requirements after abdominal hysterectomy. Anesthesiology 1992; 76: 362-7.

23. McCoy EP, Furness G, Wright PM. Patient-controlled analgesia with and without background infusion. Analgesia assessed using the demand: delivery ratio. Anaesthesia 1993; 48: 256-60.

24. Hicks CL, von Baeyer CL, Spafford PA, van Korlaar I, Goodenough B. The Faces Pain Scale-Revised: toward a common metric in pediatric pain measurement. Pain 2001; 93: 173-83.

25. Merkel SI, Voepel-Lewis T, Shayevitz JR, Malviya S. The FLACC: a behavioral scale for scoring postoperative pain in young children. Pediatr Nurs 1997; 23: 293-7.

26. Büttner W, Finke W. Analysis of behavioural and physiological parameters for the assessment of postoperative analgesic demand in newborns, infants and young children: a comprehensive report on seven consecutive studies. Paediatr Anaesth 2000; 10: 303-18.

27. Song JW, Park EY, Lee JG, Park YS, Kang BC, Shim YH. The effect of combining dexamethasone with ondansetron for nausea and vomiting associated with fentanyl-based intravenous patient-controlled analgesia. Anaesthesia 2011; 66: 263-7.

28. Kim SI, Han TH, Kil HY, Lee JS, Kim SC. Prevention of postoperative nausea and vomiting by continuous infusion of subhypnotic propofol in female patients receiving intravenous patient-controlled analgesia. Br J Anaesth 2000; 85: 898-900.

29. Takizawa E, Takizawa D, Hiraoka H, Saito S, Goto F. Disposition and pharmacodynamics of propofol during isovolaemic haemorrhage followed by crystalloid resuscitation in humans. Br J Clin Pharmacol 2006; 61: 256-61.

30. Davis JJ, Swenson JD, Hall RH, Dillon JD, Johnson KB, Egan TD, et al. Preoperative "fentanyl challenge" as a tool to estimate postoperative opioid dosing in chronic opioid-consuming patients. Anesth Analg 2005; 101: 389-95. 